\title{
Estratégias para sobreviver politicamente: Escolhas de carreiras na Câmara de Deputados do Brasil
}

\author{
Eduardo Leoni \\ Candidato a Ph.D., Columbia University \\ Carlos Pereira \\ Research Fellow - Centre for Brazilian Studies, \\ St. Antony's College, University of Oxford \\ Lúcio Rennó \\ Candidato a Ph.D., University of Pittsburgh
}

\begin{abstract}
Resumo
Os deputados federais brasileiros têm cinco escolhas principais de carreira política: retirar-se do jogo político (aposentar-se); concorrer a um cargo legislativo estadual (ambição regressiva); concorrer à reeleição (ambição estática); e concorrer a cargos mais altos (ambição progressiva). Este artigo monta um modelo para explicar as características das escolhas dos deputados com respeito a suas decisões de carreira na eleição de 1998. Sustentamos que não é a "natureza" da ambição política que determina a escolha, mas a avaliação dos riscos e custos contidos na decisão. Usou-se um modelo de regressão logit hierárquico para estimar o impacto das distintas estratégias políticas utilizadas pelos deputados em seus mandatos e suas campanhas eleitorais. Os principais resultados sugerem que os deputados com diferentes escolhas de carreira apresentam distintas estratégias durante seus mandatos, o que influencia decisivamente suas preferências do que fazem para sobreviver politicamente.
\end{abstract}

Palavras-chave: carreira política, mandato, Câmara de Deputados, estratégia política, reeleição

\begin{abstract}
The Brazilian incumbent legislators have five major choices of political career: to withdraw from the elected political game (to retire); to run for local legislative position (regressive ambition); to run for re-election (static ambition); and to run for higher offices (progressive ambition). This paper built a model to explaining the features of incumbent legislators choices regarding their career's decisions in 1998's Brazilian election. We argue that it is not the "nature" of political ambition that determines legislators' choice, but the evaluation of the risks and costs entailed in the decision. The main findings suggest that incumbents with different career's choices present distinct strategies during their mandates, which have decisive influences on their preferences of what they do in order to survive politically.
\end{abstract}

Key words: political carrer, mandate, chamber of deputies, political strategy, reelection 


\section{Introdução*}

Nas eleições gerais brasileiras de 1998, 564 deputados federais (incluindo efetivos e suplentes) ${ }^{1}$ chegaram à encruzilhada que todos os políticos do Brasil enfrentam em anos eleitorais: a decisão sobre qual cargo disputar. Dos 564 deputados, 61 decidiram se aposentar; 38 preferiram concorrer a cargos mais altos, ou seja, concorrer para senador (18), governador (8), ou vice-governador (12), o que se chama de ambição "progressiva". Oitenta por cento, ou 452 deputados ${ }^{2}$ decidiram concorrer à reeleição. Por fim, 12 deputados decidiram concorrer a deputado estadual.

Tabela 1: Distribuição de carreira política nas eleições de 1998

\begin{tabular}{|c|c|c|c|}
\hline Escolha de carreira & Total & Sucesso & Fracasso \\
\hline Aposentar-se & 61 & & \\
\hline Deputado Estadual (Ambição Regressiva) & 12 & $\begin{array}{c}6 \\
(50 \%)\end{array}$ & $\begin{array}{c}6 \\
(50 \%)\end{array}$ \\
\hline Governador & 8 & $\begin{array}{c}1 \\
(12,5 \%) \\
\end{array}$ & $\begin{array}{c}7 \\
(87,5 \%) \\
\end{array}$ \\
\hline Vice-governador & 12 & $\begin{array}{c}3 \\
(25 \%)\end{array}$ & $\begin{array}{c}9 \\
(75 \%)\end{array}$ \\
\hline Senador & 18 & $\begin{array}{c}3 \\
(17,64 \%)\end{array}$ & $\begin{array}{c}15 \\
(82,35 \%) \\
\end{array}$ \\
\hline Subtotal & 38 & $\begin{array}{c}7 \\
(18,92 \%)\end{array}$ & $\begin{array}{c}31 \\
(81,08 \%)\end{array}$ \\
\hline Reeleição (Ambição estática) & $\begin{array}{c}453 \\
(79,53 \%) \\
\end{array}$ & $\begin{array}{c}293 \\
(64,87 \%)\end{array}$ & $\begin{array}{c}160 \\
(35,13 \%) \\
\end{array}$ \\
\hline Subtotal & & $\begin{array}{c}303 \\
(61,33 \%)\end{array}$ & $\begin{array}{c}193 \\
(45,20 \%)\end{array}$ \\
\hline Total & & 564 & \\
\hline
\end{tabular}

\footnotetext{
* Versões anteriores deste trabalho foram apresentadas na conferência "Brazilian Political Institutions in Comparative Perspective: The Role of Congress in Presidential System". Centre for Brazilian Studies, University of Oxford, 2-29 de maio de 2001; no XXIII Congresso Internacional da Latin American Studies Association - LASA, Washington, DC, 6-8 de setembro de 2001; e na $5^{\text {a }}$ Conferência Anual da International Society for New Institutional Economics - ISNIE, San Francisco, Ca., 13-15 de setembro de 2001. Agradecemos a Laurence Whitehead, Mark Jones e Philip Keefer por seus comentários e sugestões nessas ocasiões.

${ }^{1}$ A amostra inclui tanto deputados eleitos como os suplentes. Para cada deputado eleito, há no Brasil um suplente que é também eleito. Alguns deles exercem o mandato por distintos períodos de tempo porque é muito comum que os deputados eleitos ganhem cargos na burocracia federal ou estadual. Uma vez que todos os membros de nossa amostra tiveram uma chance de exercer mandato por algum período de tempo e usar suas prerrogativas de deputados federais, eles foram incluídos na amostra analisada.

${ }^{2}$ É importante dizer que não incluímos em nossa amostra, por motivos óbvios, nove deputados que morreram durante seus mandatos; 33 deputados que foram eleitos prefeitos em 1996 e dois que foram eleitos vereadores na mesma eleição; dois deputados que foram nomeados para o Supremo Tribunal de Contas; e finalmente, cinco deputados que foram expulsos da Câmara de Deputados.
} 
O aspecto mais notável desses dados é a alta proporção dos legisladores que concorreram à reeleição. Trata-se de uma porcentagem mais alta da que ocorre na maioria dos outros países da América Latina (Morgenstern, a sair: Tabela 1) e isso indica claramente que não se deve negligenciar a reeleição como uma preocupação central dos deputados brasileiros. Samuels (2000), no entanto, sustentou que a ambição progressiva está também na essência da explicação dos padrões de carreira e do baixo êxito da reeleição nas legislaturas do Brasil (por volta de $65 \%$ em nossos dados). O argumento de Samuels é basicamente que os deputados mais fracos, aqueles que são mais vulneráveis eleitoralmente e menos competentes no desempenho de suas funções de representantes, concorrem à reeleição, enquanto os mais capazes concorrem a postos mais altos.

Essa explicação tem implicações sérias para o papel da Câmara de Deputados nas diretrizes políticas do país. Se a Câmara não é um locus que atrai os políticos mais eficientes, nem que estimule carreiras duradouras, onde esses políticos podem adquirir a experiência e o conhecimento necessários para se tornarem melhores servidores públicos, as chances do poder legislativo brasileiro de se tornar um ator central da formulação de políticas são desanimadoras. Por outro lado, se os políticos mais qualificados e ativos decidem ficar na Câmara, então sua influência nas decisões políticas tem melhores chances de aumentar.

Tendo em vista a posição central da escolha de carreira dos políticos para o funcionamento das legislaturas, a questão principal deste estudo é: quais são as principais razões da escolha de carreira dos deputados? Ademais, de que modo as variáveis relacionadas com a participação dos deputados na Câmara, tais como desempenho no cargo e vulnerabilidade eleitoral, influenciam a escolha de carreira?

Tomamos por suposto neste artigo que a decisão estratégica ou escolha que os legisladores fazem com relação a qual cargo vão concorrer na próxima eleição é orientada principalmente por uma auto-avaliação do desempenho no cargo e das chances de ter êxito nas eleições. Em outras palavras, as escolhas de carreira do legislador não são orientadas apenas pelas compensações do cargo pretendido, tais como remuneração mais alta ou equipe maior, mas também pela viabilidade eleitoral dessa escolha. Isto é, a utilidade maior de ser eleito para esses cargos deve ser ponderada pela sua menor probabilidade de sucesso e levar em conta os diferentes custos embutidos em cada escolha.

Para investigar se as escolhas de carreira são independentes uma das outras, aplicamos um teste de logit hierárquico que ainda não foi utilizado no estudo de padrões de carreiras políticas. O impacto das diferentes variáveis explicativas na probabilidade de escolher uma carreira também foi testado usando um modelo de logit hierárquico, oferecendo evidências dos determinantes de cálculos de carreira. Três fatores principais serão analisados: posição e desempenho institucional no cargo, características de carreira pessoal e 
Estratégias para sobreviver politicamente - Escolha de carreiras na Câmara de Deputados do Brasil

vulnerabilidade eleitoral (Hall e Houweling, 1995).

Analisamos as decisões de carreira enfrentadas pelos deputados federais brasileiros no final de seus mandatos. Portanto, não estamos preocupados com o resultado da decisão, seja de vitória ou derrota na eleição. Em vez disso, investigamos os fatores que moldam as diferentes decisões de carreira. Apoiados em estudos recentes sobre reeleição e escolha de carreira na Câmara de Deputados do Brasil, bem como na Câmara de Deputados dos Estados Unidos, formulamos um modelo teórico simples e proporcionamos testes empíricos usando dados da 50a sessão (1995-98).

\section{Ambição na Câmara de Deputados dos EUA}

O livro seminal de Schlesinger, publicado em 1966, Ambition and Politics, é o precursor e ainda uma referência essencial sobre decisões de carreira nos Estados Unidos. Examinando as características dos indivíduos que concorreram aos vários cargos e conseguiram se reeleger, ele conseguiu construir uma tipologia de políticos baseada em suas ambições políticas. Nos termos de Schlesinger, a ambição estática é o desejo ou tendência a concorrer à reeleição, isto é, a ficar no mesmo posto. Avançar para um cargo mais alto é chamado de ambição progressiva. Essa escolha, evidentemente, seria constrangida pela estrutura de oportunidades das carreiras políticas existentes.

Mas as pesquisas sobre decisões de carreira e ambição nos EUA não pararam em 1966. Seguiram-se vários trabalhos que empregaram um tratamento teórico mais analítico e análises estatísticas cada vez mais sofisticadas. Black (1972) foi o primeiro a colocar a teoria da ambição num quadro teórico de decisão. Rohde (1979) utilizou esse quadro para estudar membros da Câmara. Ele tomou por suposto que todo político, tendo a oportunidade sem custos ou riscos, escolheria o cargo mais alto. Como já foi mencionado, esses cargos proporcionam maiores recursos políticos e econômicos. Quaisquer que sejam os objetivos últimos dos legisladores, podemos pressupor que eles estariam provavelmente mais bem servidos nesses cargos. Porém, trata-se de uma escolha exigente. Os políticos são indivíduos racionais: eles sabem que existem custos substancialmente maiores na disputa desses cargos. Além disso, eles ponderam a utilidade de obter um posto mais alto com as probabilidades (menores) de ganhar a eleição.

Brace (1984) deu seguimento à pesquisa de Rohde utilizando uma análise probit, sendo capaz de estimar um modelo de regressão de seleção de carreira. Por fim, como discutiremos adiante, Kiewiet e Zeng aperfeiçoaram a adequação entre os modelos econométrico e de teoria da decisão, conseguindo também fundir a pesquisa sobre ambição com aquela sobre aposentadoria na Câmara de Deputados norte-americana. 


\section{Escolha de carreira e reeleição no Brasil}

Obviamente, o Brasil não é os Estados Unidos e a estrutura de carreira e o sistema partidário, para não mencionar as regras eleitorais, são muito diferentes. Portanto, é importante entender alguns dos aspectos centrais do sistema eleitoral brasileiro antes de delinear nosso modelo.

No Brasil, a eleição para a Câmara de Deputados é feita por representação proporcional, com listas abertas. Nesse sistema, as cadeiras são distribuídas em proporção à porcentagem do total de votos que cada partido recebe. Porém, como a grande maioria dos eleitores apóia candidatos, em vez de partidos, a eleição depende basicamente da capacidade dos candidatos de obterem votos para si próprios.

Ademais, a quantidade total de votos obtida pelos candidatos determina a ordem deles na lista do partido. Em outras palavras, o partido não controla nem determina quem serão seus representantes. As cédulas, por exemplo, não contêm o nome dos candidatos e, portanto, o partido não pode listá-los numa ordem de preferência. Ao entrar na cabine de votação, os eleitores devem saber o nome ou o número de seus candidatos. Cada político deve contar com seus próprios recursos e sua própria base eleitoral para se tornar candidato.

Os candidatos do partido são escolhidos por meio de eleições indiretas chamadas convenções, e são eleitos por delegados do partido. De acordo com Mainwaring (1999, p.249), embora as convenções tenham autoridade formal sobre a seleção de candidatos, elas quase sempre ratificam acordos que foram feitos por dirigentes do partido e autoridades do governo antes da realização da convenção. Em geral, apresenta-se à convenção uma chapa única, combinada e definida anteriormente.

Portanto, o sistema eleitoral brasileiro, o mecanismo de seleção dos candidatos e algumas regras partidárias criam incentivos para um comportamento individualista e antipartidário. O sistema eleitoral ajuda a explicar o comportamento individualista dos políticos na arena eleitoral e tem contribuído para a fraca institucionalização do sistema partidário.

Não há limite para o número de mandatos e os partidos são obrigados a indicar os deputados que pretendem se reeleger sem levar em conta o comportamento deles na legislatura anterior. São os chamados candidatos natos, que têm o direito de concorrer ao mesmo cargo na eleição seguinte. É óbvio que isso libera os políticos da influência dos líderes do partido e, em conseqüência, enfraquece a noção de liderança.

O processo de seleção dos candidatos também é muito afetado pelo federalismo. A política local, prefeitos e governadores, são forças poderosas com significativa autonomia em relação ao governo federal. O controle exercido pelo 
governador de estado e pelos políticos locais sobre a ação dos legisladores federais é amplamente conhecido. Pode-se estabelecer uma correlação direta entre essa influência e a seleção dos candidatos ao Legislativo. No centro do processo está a premissa de que a seleção ocorre basicamente no nível estadual ou municipal. Um dos resultados disso é a criação de partidos estaduais descentralizados, em vez de partidos nacionais centralizados. Para garantir sua indicação, o candidato precisa fazer alianças políticas municipais e estaduais, diminuindo o impacto da linha política do partido e, ao mesmo tempo, orientando o comportamento do legislador no sentido de atender a clientela local.

Além disso, o Congresso brasileiro não é de forma alguma tão institucionalizado quanto o norte-americano. Se seguirmos a discussão de Polsby (1968) da institucionalização, existe no Congresso brasileiro uma divisão do trabalho em comissões, mas estas não são tão poderosas como as existentes nos EUA, simplesmente porque o poder legislativo no Brasil não tem a palavra final sobre gastos orçamentários. Ademais, há mais oscilação nos padrões da escolha de carreira no Brasil do que nos Estados Unidos. Isto é, a rotatividade é mais alta e as carreiras políticas não são tão estáveis (Samuels, a sair).

O estudo das carreiras políticas no Brasil tem se concentrado principalmente nas questões de recrutamento e retenção dos legisladores nacionais ${ }^{3}$. Mais recentemente, Samuels (2000) analisou as decisões de carreira das legislaturas brasileiras utilizando o modelo proposto por Schlesinger. Ele destaca que embora as instituições políticas e eleitorais do país pareçam engendrar carreiras legislativas longas, a rotatividade é relativamente alta no Brasil. Samuels sustenta que isso é conseqüência da natureza da ambição política no país e do alto nível de competição decorrente das regras eleitorais. Usando a tipologia da ambição, ele afirma que os políticos brasileiros possuem um componente mais alto de ambição progressiva, em vez de estática, orientando suas carreiras para os cargos executivos principalmente, mas não de modo exclusivo, do nível municipal.

O argumento básico de Samuels é que os legisladores com melhores qualificações, ou seja, aqueles que esperam ter um grau maior de sucesso eleitoral, concorrem para postos mais altos de senador, prefeito e governador. Desse modo, quem concorre à reeleição são aqueles mais vulneráveis eleitoralmente. Em conseqüência, a rotatividade é alta. Na visão de Samuels o principal enigma das eleições legislativas do Brasil não é a reeleição, mas a alta taxa de rotatividade.

Porém, um fator central que está ausente da argumentação de Samuels é o pressuposto de Rohde sobre os congressistas americanos: se tiverem a chance de escolher entre o posto atual e o de senador, sem custos adicionais, os deputados preferirão imediatamente a posição mais alta. Em conseqüência, sustentamos que não

\footnotetext{
${ }^{3}$ Para uma excelente revisão, ver Santos, 1999.
} 
é a "natureza" da ambição política que determina a predominância da ambição estática no caso dos Estados Unidos, mas a avaliação dos riscos e custos decorrentes da decisão tal como percebidos por legisladores presumidamente racionais. Portanto, é provável que os mais qualificados busquem cargos mais altos, mas isso não significa que somente os menos qualificados sejam forçados a buscar a reeleição. O risco de concorrer a um posto mais difícil de conquistar é um constrangimento no rol de escolhas de carreira com que se defrontam os deputados, inclusive os mais competentes. Isso é especialmente verdade porque as regras que comandam as eleições para cargos mais altos (Senado e poder executivo em todos os níveis) são diferentes daquelas que organizam as eleições para a Câmara de Deputados. Como dissemos, as eleições para a câmara baixa brasileira adotam um sistema de Representação Proporcional de Lista Aberta, enquanto as eleições para o Executivo são feitas de acordo com um sistema de maioria em dois turnos e as do Senado usam um sistema de pluralidade. Portanto, o custo de passar do primeiro sistema (em que a fragmentação do voto entre vários candidatos é muito alta e a quantidade total de votos para se eleger não é excessiva) para o de maioria (em que o número de candidatos é muito menor e o de votos exigidos para ganhar muito maior) é muito alto ${ }^{4}$.

\section{Delineando a teoria}

Para modelar explicitamente as utilidades e probabilidades ligadas à opção de carreira, é útil seguir o modelo de utilidade esperada que já se mostrou altamente informativo no caso da Câmara de Deputados americana e já proposto para analisar o caso brasileiro (Santos, 1999).

Kiewiet e Zeng (1993) sustentam que as escolhas entre faposentadoria; reeleição\} e entre \{reeleição; cargos mais altos\} não são independentes:

“Por exemplo, estudos anteriores de aposentadoria voluntária não consideraram o impacto de variáveis fundamentais que afetam a ambição progressiva [...] É verdade que essas variáveis não afetam provavelmente a probabilidade condicional de aposentadoria versus buscar a reeleição. Porém, se elas aumentam a probabilidade de os membros da Câmara buscarem cargos mais altos, elas diminuem necessariamente a probabilidade de eles escolherem 0 subconjunto de \{aposentadoria, reeleição\}e, assim, diminuem necessariamente a probabilidade de aposentadoria".

\footnotetext{
${ }^{4}$ Outro aspecto das eleições para a câmara baixa brasileira é que se podem formar coalizões de vários partidos e é o total de votos de todos os candidatos e partidos da coalizão que determina se a coalizão alcançou o quociente eleitoral - número de votos dividido pelo número de cadeiras por distrito. Isso torna mais fácil atingir o quociente eleitoral (Nicolau, 1999).
} 
No final do mandato, os legisladores têm o conjunto de escolha $J=\left\{a_{1}, a_{2}\right.$, $\left.\ldots a_{k}\right\}$, onde $a_{1}=$ aposentar-se, $a_{2} \ldots a_{k}=$ concorrer a vários cargos.

As utilidades esperadas são as seguintes. Aposentar-se: $E\left[U\left(a_{1}\right)\right]=U\left(a_{1}\right)$

Se o deputado decide se aposentar, não há probabilidades envolvidas. 0 legislador receberá a utilidade de se aposentar com certeza. Seja $c_{1}$ o custo de escolher $a_{1} ; q_{s}$ a probabilidade de sucesso, que depende de sua ação; $U_{s}\left(a_{i}\right) a$ utilidade de sucesso de ação $a_{i} ; U_{f}\left(a_{i}\right)$ a utilidade de fracasso de ação $a_{i}$, a utilidade esperada de concorrer a um determinado cargo é:

Concorrer a Cargo $a_{i}: E\left[U\left(a_{i}\right)\right]=q_{s}\left(a_{i}\right) U_{s}\left(a_{i}\right)+\left(1-q_{s}\left(a_{i}\right) U\left(a_{i}\right)-c_{i}\right.$

Definindo a utilidade de fracasso de concorrer a qualquer cargo como a utilidade de aposentar-se.

$\mathrm{U}_{\mathrm{f}}\left(\mathrm{a}_{\mathrm{i}}\right)=\mathrm{U}\left(\mathrm{a}_{1}\right)$

A utilidade esperada simplifica-se então para:

$E\left[U\left(a_{i}\right)\right]=a_{s}\left(a_{i}\right) U_{s}\left(a_{i}\right)+\left(1-q_{s}\left(a_{i}\right)\right) U\left(a_{1}\right)-c_{i}$

O próximo passo é supor que os legisladores comparam as utilidades esperadas das ações disponíveis e escolhem concorrer ao cargo no qual a utilidade esperada é a maior. Ou seja, cada indivíduo escolhe alternativa $a_{j}$ em J se e somente $E\left[U\left(a_{j}\right)\right]>E\left[U\left(a_{n}\right)\right]$ para todo $n$ em $J, n \neq j$.

Nesta visão, a escolha do legislador depende da utilidade de (e variáveis independentes explicando) todas as outras opções. Para uma escolha em J, o cálculo relevante feito é a diferença entre a utilidade esperada de concorrer $a a_{j}$ e a utilidade esperada de concorrer a todas as outras opções. O problema é que não sabemos as utilidades esperadas reais nem observamos cada variável relevante. Fazemos, portanto, declarações probabilísticas e deveríamos estimar conformemente um modelo econométrico.

\section{Questões econométricas}

Tal como Kiewiet e Zeng, escolhemos aqui não estimar um modelo logístico multinomial $^{5}$. Nossas dúvidas surgem das utilidades esperadas delineadas acima, onde a decisão por qualquer alternativa depende das utilidades de todas as outras opções disponíveis. No modelo de logit multinomial, as probabilidades de escolher $\mathrm{j}$ sobre a categoria de base $\mathrm{k}$ é dada por:

\footnotetext{
${ }^{5}$ Numa versão anterior deste trabalho (Pereira e Rennó, 2001), utilizamos um modelo logístico multinomial. O resultado mais importante desses testes confirmou nossa predição de que diferentes escolhas de carreira estão orientadas por diferentes estratégias dos legisladores durante seus mandatos.
} 


$$
\operatorname{Pr}\left(Y_{i}=j\right)=\frac{e^{\beta{ }_{j} x_{i}}}{1+\sum_{k=1}^{J} e^{\beta{ }^{\prime}{ }_{k} x_{i}}}, \quad \text { para } j=1, \ldots, J,
$$

Observe-se que os atributos de alternativas diferentes de k ou j não entram nas probabilidades. Ou seja, o pressuposto da "Independência de Alternativas Irrelevantes" deve valer. Em conseqüência, pode-se mostrar que a inclusão (ou exclusão) de qualquer opinião deve afetar a odds ratio de cada alternativa exatamente do mesmo modo. Além disso, se a probabilidade de alguma alternativa em j aumenta, "a propriedade IIA requer que as outras alternativas caíam precisamente de forma a manter suas probabilidades relativas iniciais" (Zhang e Hoffman 1993, p.197). Em conseqüência, se algumas das alternativas disponíveis são substitutos fechados, essa propriedade fará com que o modelo forneça predições incorretas. Dado o nosso modelo teórico, bem como os resultados dos Testes IIA em um trabalho anterior (2001), não esperamos que a escolha modelada exiba essa propriedade.

Porém, se pudermos agrupar as alternativas de modo significativo, há outro modelo econométrico à disposição. Mais apropriado, esse modelo permite violações do pressuposto IIA na decisão entres os grupos de alternativas, mas ainda exige que o pressuposto seja válido dentro dos grupos.

Para ser mais preciso, o modelo de logit hierárquico (também conhecido como Valor Extremo Generalizado ou GEV) não exige que o legislador tome sua decisão seqüencialmente. Na verdade, o modelo é derivado “supondo-se que o tomador de decisão faz uma escolha, a saber, uma do conjunto disponível [...] A seqüência de probabilidades no modelo GEV é simplesmente um método para o pesquisador representar a falta de IIA entre as probabilidades de escolha" (Train, 1986, p.72). Nossa principal preocupação era modelar a dependência entre as alternativas, em vez de pressupô-la constantemente. A abordagem hierárquica aproveita o agrupamento "natural" das alternativas na estimativa e reflete mais claramente nossas observações substantivas ${ }^{6}$.

A variável dependente é a escolha do legislador no final de seu mandato. Isso significa que estão excluídos os deputados que deixaram a cadeira quando foram eleitos prefeitos nas eleições municipais, ou foram nomeados para postos permanentes na burocracia, entre outras opções de saída antes do final do mandato.

Aqueles que concorreram a governador, vice-governador e senador estão agrupados na categoria dos que concorrem a cargos mais altos. Vamos pressupor (ao contrário do caso americano) que todos os legisladores têm uma oportunidade

\footnotetext{
${ }^{6}$ Estimamos nosso modelo no pacote estatístico STATA 7.0 em um PC com Intel, com o comando nlogit. Isso produz estimativas de informação total e máxima probabilidade.
} 
de concorrer a cargo mais alto. Essa suposição é aproximadamente verdade no Brasil. Mesmo que não fosse, a possibilidade de mudar de partido é muito menos custosa do que nos Estados Unidos, o que torna o conceito de posição "aberta" de governador ou senador um tanto obscura. A definição do grupo que concorre à reeleição é simples e os membros que se aposentam são aqueles de nossa amostra que não concorreram a nenhum posto na eleição de 1998.

Os deputados federais que concorreram a uma cadeira nas assembléias legislativas estaduais foram um problema grave em nossas estimativas. O motivo foi o pequeno número deles (somente 12) que optaram por isso. Tentamos vários modelos com esta escolha incluída e, na maioria deles, a estimativa não convergiu. Enquanto não tivermos mais dados (de eleições passadas e futuras), decidimos excluir essa opção da estimativa.

O modelo de logit hierárquico requer que especifiquemos quais variáveis afetam cada nível de decisão, de modo a que possamos estimar um modelo em que algumas variáveis influem na decisão entre aposentar-se; concorrer a cargo mais alto ou reeleição\}, enquanto outras têm um efeito apenas sobre a decisão entre concorrer a cargo mais alto e reeleição. Essa flexibilidade exige que expliquemos qual decisão uma dada variável independente está afetando. O arranjo de decisão que escolhemos pode ser representado graficamente pela seguinte estrutura em árvore.

Figura 1: Modelo de escolha da carreira política

Legislador

Aposentar-se Concorrer a algum cargo

Concorrer à reeleição Concorrer a cargo mais alto

Ou seja, seguindo Hall e Houweling (1995), lançamos a hipótese de que a opção de aposentadoria é muito diferente de concorrer à reeleição ou a um cargo mais alto. Mas diferente desses autores, que escolheram enfocar exclusivamente os correlatos de aposentar-se e ignoraram a exploração das diferenças entre as motivações da ambição estática e progressiva, nós podemos estimar modelos para todas essas decisões simultaneamente, devido ao uso de equações de logit hierárquico. Escolhemos essa conFiguração de escolhas de carreira por dois motivos principais: 1) concorrer a esses cargos implica custos importantes que os indivíduos que decidem não concorrer a qualquer eleição não precisam suportar; 2) deputados, senadores e governadores/vice-governadores partilham o distrito eleitoral. Esperamos então que as duas opções eleitorais sejam mais semelhantes 
entre si do que a opção de aposentar-se e qualquer uma delas.

\section{Correlatos da escolha de carreira}

O próximo passo da explicação da escolha de carreira é modelar o impacto dos diferentes fatores que influenciam as decisões dos deputados. Para recapitular, as variáveis podem influenciar a escolha de carreira de duas maneiras: podem afetar os componentes de utilidade, aumentando (ou diminuindo) o valor de permanecer em determinado cargo; e podem afetar as probabilidades de obter um determinado resultado.

Espera-se que muitas das variáveis que afetam a probabilidade de ser reeleito afetem também as probabilidades de se eleger para as posições mais altas. O efeito líquido é então uma questão empírica, e assim o deixamos.

Idade: Tal como nas pesquisas anteriores na Câmara de Deputados dos EUA (Kiewiet e Zeng, 1993; Hall, 1996), tomamos por hipótese que a idade aumenta a utilidade de se aposentar. A idade deveria afetar também a utilidade de um cargo mais alto. Embora esperemos um efeito linear da idade na decisão de se aposentar, incluímos um termo quadrático na estimativa entre as escolhas de cargo mais alto e reeleição.

Na Câmara de Deputados americana, Brace (1984) descobriu que o efeito linear era positivo e o efeito quadrático negativo na escolha entre reeleição e concorrer a um posto mais alto ${ }^{7}$. Suspeitamos que o padrão encontrado por Brace é uma função da regra de antigüidade do sistema de comissões, que aumenta o valor da detenção de cargo longa. No Brasil, não existe atualmente um sistema como esse. Suspeitamos, portanto, que membros da Câmara relativamente jovens e relativamente antigos tentam concorrer a cargos mais altos, predição oposta à de Brace. Embora essa hipótese não tenha relevância teórica para nossas preocupações normativas, é necessário controlá-la a fim de especificar corretamente o modelo.

Posições institucionais: Voltamo-nos agora para o termo concernente à utilidade de ficar no cargo. Pesquisas anteriores sobre a Câmara de Deputados brasileira (Figueiredo e Limongi, 1995, 1996, 1997; Pereira e Mueller, 2000) concluíram que a distribuição de poder dentro dessa instituição é altamente concentrada nas mãos dos líderes dos partidos e, portanto, que os postos institucionais (presidente, vice-

\footnotetext{
${ }^{7}$ Brace não incluiu a decisão de se aposentar em sua análise.
} 
Estratégias para sobreviver politicamente - Escolha de carreiras na Câmara de Deputados do Brasil

presidente, etc.) são posições de poder. Uma vez que aumentam as recompensas de ficar no cargo, esperamos que tais variáveis tenham um impacto positivo sobre concorrer à reeleição.

Comissões permanentes e especiais: Embora o sistema de comissões não seja tão institucionalizado como na Câmara americana, esperamos que o poder relativo dos membros mais antigos das comissões tenha conseqüências importantes na escolha de carreira. Pereira e Mueller (2000) já se referiram a evidências claras que enfatizam a existência de ganhos informacionais obtidos pelo plenário da Câmara e pelo Executivo - quando as comissões são representativas das preferências do Executivo. Eles demonstraram também que há fortes indícios de que o Executivo age estrategicamente no Congresso, substituindo membros infiéis por confiáveis, a fim de garantir as vitórias de suas preferências. Esse pressuposto foi também confirmado pelas respostas de vários legisladores que disseram que suas escolhas de comissões foi negociada ou mesmo imposta pelos líderes dos partidos. Desse modo, torna-se difícil explicar a preocupação do Executivo em designar membros favoráveis, se não houver relevância ligada a tê-los na comissão.

Portanto, criamos "dummies" que discriminam os efeitos de ser líder numa comissão permanente daqueles de ser líder numa comissão especial. Essas comissões especiais têm uma cobertura maior da mídia e esperamos que a presença nessas comissões aumente a probabilidade de concorrer a um posto mais alto. Por outro lado, as posições nas comissões permanentes deveriam aumentar a probabilidade de escolher a reeleição ${ }^{8}$, pois são uma indicação de poder dentro da Câmara e de ambição intra-câmara (Hall e van Houweling, 1995).

Por outro lado, esperamos que ambos os tipos de comissão aumentem a probabilidade de concorrer a um cargo, seja à reeleição ou a um cargo mais alto. Não temos nenhum motivo para predizer que a liderança numa comissão permanente ou especial teria efeitos diferentes sobre a decisão de concorrer a algum cargo. Tudo o que esperamos é que essas posições de poder aumentem a utilidade de concorrer a algum cargo. Portanto, combinamos as duas variáveis "dummy", onde 1 é deter alguma posição de liderança em comissão e zero é não ter nenhuma, na equação que distingue os que concorrem a algum cargo daqueles que se aposentam.

Ideologia: Medimos ideologia pelos escores w-nominates dos legisladores (Poole e Rosenthal, 1997). Eles baseiam-se no comportamento dos deputados nas votações

\footnotetext{
${ }^{8}$ Esperamos que a participação em comissões permanentes também afete positivamente a probabilidade, e não apenas a utilidade, de concorrer à reeleição, uma vez que essa variável tem um efeito positivo sobre o sucesso na reeleição em Pereira e Rennó, 2000. Esse efeito é congruente com nossa hipótese anterior de que a presença em comissões permanentes aumenta a utilidade de manter o cargo.
} 
nominais e se tornaram um padrão de facto na mensuração de preferências de legisladores no cenário político americano. Leoni (2000; 2001) calculou os escores para os legisladores brasileiros que usamos aqui.

As estimativas produzidas por esse procedimento de scalling na Câmara de Deputados estão, em larga medida, de acordo com a visão comum do campo. Por exemplo, os membros do PT estão na extrema esquerda e a maioria dos membros do PFL está na direita9 .

Os membros da ala esquerda do espectro ideológico estão mais distantes dos resultados vencedores e possivelmente derivam menos utilidade da permanência no cargo por esse motivo. Então estabelecemos a hipótese de que eles têm maior probabilidade de deixar voluntariamente a Câmara.

Antigüidade: As eleições brasileiras de 1986 foram as primeiras depois que o governo civil retomou o poder, após mais de vinte anos de regime militar, durante o qual o Legislativo não teve muita participação nas decisões políticas. Em conseqüência, é justo dizer que não esperamos que os membros tenham carreiras longas em tal corpo legislativo (Santos, 2001). Desse modo, definimos antigüidade como o número de mandatos consecutivos que o deputado teve desde a $48^{a}$ legislatura. Esperamos que isso tenha um efeito positivo sobre a candidatura à reeleição. Tomamos como hipótese que os legisladores mais antigos possuem um conhecimento operacional valioso sobre a instituição e suas regras e, portanto, derivam mais utilidade em permanecer nela.

Partidos: Introduzimos uma variável "dummy" que reflete a participação na coalizão do presidente Fernando Henrique Cardoso. Esperamos que essa variável aumente a utilidade de permanecer no cargo, refletindo a maior utilidade de ter status de maioria. É importante destacar também o fato de ser membro do PT, pois esse partido é qualitativamente diferente daqueles da direita. Esse partido tem uma das maiores porcentagens de votos na legenda, o que certamente traz incentivos diferentes. É difícil predizer as conseqüências de pertencer ao PT. Uma possibilidade é que esse partido reveze seus membros entre postos estaduais e federais. Outra possibilidade é que os membros do PT, estando tão à esquerda do espectro ideológico (Leoni, 2000), sejam ideologicamente frustrados. Em ambos os casos, esperamos que eles apresentem uma probabilidade maior de sair da Câmara.

Dotação orçamentária: Pereira (2000) e Pereira e Rennó (2001) estimaram um

\footnotetext{
${ }^{9}$ Além disso, a análise indica que o espaço ideológico tem baixa dimensionalidade, com a primeira dimensão predizendo corretamente $90 \%$ dos votos das votações nominais na sessão que analisamos neste trabalho (a $50^{\mathrm{a}}$ ). Ambos os resultados geram mais confiança no uso dessa medida de ideologia no cenário da Câmara Federal brasileira.
} 
modelo para predizer reeleição e uma das principais descobertas está relacionada com o orçamento. Ela mede a porcentagem média anual das emendas individuais dos deputados aprovadas no orçamento federal e dotadas pelo governo de 1996 a 1998. É importante sublinhar que no Brasil, é o Executivo que decide a liberação das verbas, o Congresso apenas autoriza o orçamento. Esperamos que aqueles com maior sucesso na dotação de verbas tentarão se reeleger, uma vez que isso aumenta a probabilidade de vitória (ver também Pereira, 2000; Pereira e Mueller, 2001).

Voto em 1994: Essa variável mede o sucesso anterior do deputado no distrito. É medida como o número de cotas eleitorais que o candidato teve na eleição anterior e é uma indicação de quão seguro eleitoralmente é o deputado. Esperamos um efeito positivo do sucesso eleitoral anterior sobre a escolha de concorrer a um cargo mais alto.

Concentração eleitoral: Os deputados com voto concentrado em seu município mais importante não têm provavelmente a força eleitoral para obter apoio nas várias municipalidades incluídas no distrito eleitoral. No Brasil, os distritos correspondem a todo o estado e incluem eleitorados muito diversificados e vários municípios. Desse modo, os candidatos com voto concentrado concorreram com menor probabilidade a cargos mais altos, pois não são suficientemente conhecidos em todo o distrito para encarar uma eleição majoritária. Os que contam com votos mais espalhados e são mais conhecidos em mais lugares sentem-se provavelmente mais confiantes para assumir o risco de concorrer a um posto mais alto. Portanto, esperamos que os legisladores com menor concentração de votos concorram com maior probabilidade a cargos mais altos.

Número de cadeiras do distrito: Essa hipótese está também relacionada aos níveis de competição eleitoral que um candidato enfrenta dentro do distrito. No caso da Câmara de Deputados norte-americana, Rohde e Brace sustentam que é a comunidade entre o distrito da Câmara, o do Senado e do governo estadual nos pequenos estados que aumenta a probabilidade do deputado dos estados menores concorrer a cargos mais altos. Evidentemente, não há variação nesse aspecto no caso brasileiro, pois os distritos da Câmara são os mesmos dos governadores e senadores.

Contudo, é razoável esperar que o número de candidatos mais fortes nos estados mais populosos seja maior do que nos estados menores. A hipótese de Kiewiet e Zeng de que "os membros dos estados grandes enfrentam um grupo maior de candidatos fortes-outros membros da Câmara como eles mesmos" ( $p$. 933) é mais facilmente adaptável ao caso brasileiro do que a de Rohde e Brace. 
Conforme Kiewiet e Zeng, criamos uma medida do contexto eleitoral em que os deputados candidatos estão encaixados tomando o log da magnitude do distrito, ou número de cadeiras em cada distrito. Nossa hipótese é que quanto maior a magnitude do distrito, menor a probabilidade de o deputado se candidatar a postos mais altos nesses distritos, pois o conjunto de "candidatos fortes" nesses distritos é maior.

\section{Resultados}

A Tabela 2 mostra a média das variáveis independentes. À primeira vista, muitas de nossas variáveis independentes estão de acordo com nossas predições hipotéticas. Observe-se que apresentamos também as médias das variáveis independentes para o grupo que escolheu concorrer à assembléia legislativa estadual. A partir da Tabela 1, sabemos que esse grupo se deu mal na eleição: somente $50 \%$ deles conseguiram se eleger, e isso para uma posição que exigia menos votos do que haviam tido anteriormente ${ }^{10}$. A partir da Tabela das médias descobrimos também que eles tiveram a mais baixa classificação média em orçamento dotado e participação em comissões permanentes e especiais, junto com outras variáveis.

Tabela 2: Médias das variáveis independentes em cada grupo

\begin{tabular}{|l|c|c|c|c||}
\hline & Aposentar-se & $\begin{array}{c}\text { Deputado } \\
\text { Estadual }\end{array}$ & Reeleição & $\begin{array}{c}\text { Cargo } \\
\text { mais alto }\end{array}$ \\
\hline \hline Idade & 55,70 & 51,36 & 51,35 & 53,83 \\
\hline \hline Ladeiras do distrito & 3,17 & 3,44 & 3,27 & 2,92 \\
\hline Membro de coalizão & 0,77 & 0,55 & 0,74 & 0,72 \\
\hline Ideologia & 0,15 & 0,01 & 0,20 & $-0,05$ \\
\hline PT eleitoral em & 0,11 & 0,18 & 0,08 & 0,25 \\
\hline Votos em 1994 & $-0,28$ & $-0,11$ & 0,00 & 0,08 \\
\hline Concentração & 0,32 & 0,49 & 0,39 & 0,37 \\
\hline 1994 & 0,95 & 0,75 & 1,37 & 1,34 \\
\hline Antigüidade & 22,97 & 21,76 & 33,73 & 37,97 \\
\hline Dotação & 0,35 & 0,18 & 0,46 & 0,44 \\
\hline \hline Qualquer comissão & 0,16 & 0,09 & 0,17 & 0,33 \\
\hline Comissão especial & 0,19 & 0,18 & 0,36 & 0,22 \\
\hline Comissão permanente & 0,00 & 0,00 & 0,05 & 0,03 \\
\hline Posição da câmara
\end{tabular}

\footnotetext{
${ }^{10}$ Os limites do distrito para os deputados estaduais são os mesmos dos deputados federais. Porém, há sempre mais cadeiras nas assembléias legislativas do que assentos alocados ao estado na Câmara Federal.
} 
Uma hipótese plausível é que os deputados estaduais são mais vulneráveis eleitoralmente e, portanto, escolhem concorrer a um cargo mais baixo. Isto é, os legisladores que esperam poucas probabilidades de se reeleger (e portanto têm chances ainda menores de se elegerem para um cargo mais alto) preferem concorrer a um posto mais baixo e mais seguro. Eles ainda batalham por um cargo público e, portanto, são ambiciosos, mas de modo muito realista, optam por concorrer a um cargo com recursos menores, status menor e mais fácil de vencer. Usamos uma expressão que é um oximoro - "ambição regressiva" - para caracterizar essa escolha. Infelizmente, não pudemos fazer um teste multivariado para essa hipótese pelos motivos já explicados, mas está claro que esses deputados têm um desempenho pior tanto dentro da Câmara como em eleições anteriores do que aqueles que escolhem concorrer à reeleição ou a um cargo mais alto, indicando que os piores deputados tendem a deixar a Câmara.

A Tabela 3 mostra os resultados do modelo de logit hierárquico que estimamos. É importante dizer que aplicamos esse teste não para estimar a significação ou o impacto relevante de nossas variáveis independentes, mas para testar a independência de alternativas entre carreiras políticas. Como podemos ver, nem todas as variáveis entram em ambos os estágios, conforme nossas expectativas teóricas ${ }^{11}$. Porém, como observação geral, os resultados são bastante impressionantes: sete de todas as variáveis incluídas tiveram coeficientes significativos no nível de $5 \%$ em ambas as equações, 1 sendo mais significante no nível de $10 \%$.

\footnotetext{
${ }^{11}$ A fim de verificar se os incentivos para deixar a Câmara de Deputados criados pelas oportunidades de carreira privada têm impacto sobre a escolha de carreira política, criamos duas variáveis dummy indicando se o deputado era um empresário ou um burocrata antes de se tornar deputado federal. Em nossa visão, esses são indicadores limitados de outras oportunidades potenciais de carreira fora da Câmara, mas não tivemos outros proxies. Uma vez que não foram estatisticamente significativos, optamos por deixá-los de fora do modelo e apenas os mencionamos en passant.
} 
OPINIÃO PÚBLICA, Campinas, Vol IX, no 1, 2003, pp. 44-67

Tabela 3. Modelo de logit hierárquico de escolhas de carreiras

\begin{tabular}{|c|c|c|c|c|c|c|}
\hline & Coeficiente & Erro est. & $\mathbf{z}$ & $\mathrm{P}>|\mathrm{z}|$ & \multicolumn{2}{|c|}{ Intervalo Conf. 95\% } \\
\hline \multicolumn{7}{|c|}{ concorrer a cargo mais alto $=1$; conc. a reeleição $=0$} \\
\hline dummy conc. a cargo mais alto & 1.430 & 3.884 & 0.370 & 0.713 & -6.182 & 9.042 \\
\hline posição de poder & -0.724 & 1.118 & $\mid-0.650$ & 0.517 & -2.916 & 1.467 \\
\hline idade & -0.221 & 0.139 & -1.600 & 0.110 & -0.493 & 0.050 \\
\hline idade^2 & 0.003 & 0.001 & 2.070 & 0.039 & 0.000 & 0.005 \\
\hline $\log \#$ cadeiras distritais & -0.916 & 0.334 & -2.740 & 0.006 & -1.571 & -0.261 \\
\hline concentração eleitoral em 1994 & -0.845 & 0.900 & -0.940 & 0.348 & -2.609 & 0.920 \\
\hline antigüidade & -0.062 & 0.264 & -0.240 & 0.813 & -0.580 & 0.455 \\
\hline membro da coalizão & 3.283 & 1.251 & 2.620 & 0.009 & 0.831 & 5.375 \\
\hline ideologia & -2.951 & 0.875 & -3.370 & 0.001 & -4.666 & -1.237 \\
\hline membro do PT & 2.552 & 1.264 & 2.020 & 0.043 & 0.075 & 5.029 \\
\hline comissão permanente & -0.699 & 0.439 & -1.590 & 0.112 & -1.560 & 0.162 \\
\hline comissão especial & 1.129 & 0.468 & 2.410 & 0.016 & 0.211 & 2.047 \\
\hline$\%$ dotada & 0.014 & 0.012 & 1.190 & 0.234 & -0.009 & 0.037 \\
\hline votos em 1994 & 0.089 & 0.170 & 0.520 & 0.603 & -0.245 & 0.422 \\
\hline \multirow{3}{*}{$\begin{array}{l}\text { concorrer a qualquer posto }=1 ; \\
\text { aposentar-se }=0 \\
\text { dummy qualquer posto }\end{array}$} & & & & & & \\
\hline & 2.773 & 1.058 & 2.620 & 0.009 & 0.699 & 4.846 \\
\hline & & & & & & \\
\hline idade & -0.036 & 0.017 & -2.160 & 0.031 & -0.069 & -0.003 \\
\hline Antigüidade & 0.186 & 0.183 & 1.020 & 0.309 & -0.172 & 0.544 \\
\hline membro da coalizão & -0.398 & 0.562 & -0.710 & 0.479 & -1.500 & 0.704 \\
\hline membro do PT & -0.079 & 0.781 & -0.100 & 0.920 & -1.609 & 1.451 \\
\hline Ideologia & -0.064 & 0.650 & -0.100 & 0.922 & -1.337 & 1.210 \\
\hline$\%$ dotada & 0.028 & 0.009 & 3.100 & 0.002 & 0.010 & 0.045 \\
\hline votos em 1994 & 0.361 & 0.194 & 1.860 & 0.063 & -0.020 & 0.742 \\
\hline líder de qualquer comissão & 0.201 & 0.326 & 0.620 & 0.538 & -0.438 & 0.839 \\
\hline concorrer a qualquer cargo & -1.096 & 1.117 & 0.326 & 0.326 & -3.28655 & 1.093261 \\
\hline aposentar-se & 1. & . & . & . & . & \\
\hline
\end{tabular}

Teste LR de homoscedasticidade (iv = 1): chi2 (1) = 3.37

Prob $>$ chi2 $=0.0663$

LOGIT HIERÁRQUICO

NÚMERO DE OBS $=536$

LR CH2 (24) $=656.633$

LOG LIKELLIHOOD $=-260.53968$

$\mathrm{PROB}>\mathrm{CH} 2=0.0000$

O teste de likelihood ratio na última linha é um dos testes disponíveis do pressuposto de independência de alternativas irrelevantes. A hipótese nula é que os valores inclusivos são todos iguais a zero e poderíamos ter estimado da mesma forma um logit multinomial. Esse resultado nos deixa mais confiantes de que nosso investimento em uma técnica estimativa mais flexível valeu a pena, uma vez que rejeitamos o nulo com um valor-p de 0.07 . 
É hora de reiterar que a mudança de probabilidade estimada não é condicional sobre concorrer ou não a um cargo. As utilidades esperadas, bem como os vários testes IIA que realizamos, nos informam que cálculos dependentes das escolhas feitas não são apropriados. Na verdade, o principal objetivo de estimar um logit hierárquico era obter essas estimativas incondicionais.

Como não estamos interessados simplesmente na significação estatística das variáveis, mas em seu impacto real sobre as diferentes escolhas de carreiras, concentraremos nossa análise em como as mudanças numa variável independente (estatisticamente significativa) selecionada alteram a probabilidade de escolher uma alternativa quando todas as outras variáveis são mantidas constantes.

Escolhemos manter as variáveis independentes em seus valores médios, ao mesmo tempo em que mudamos as variáveis de interesse contínuas dos valores médios para um desvio padrão acima da média, e as variáveis dummy de zero para um. A Tabela 4 apresenta os resultados.

Tabela 4: Mudança predita em probabilidades

\begin{tabular}{||l||c|c|c|c||}
\hline & mudança & Aposentar-se & cargos + altos & reeleição \\
\hline \hline Idade e Idade 2 & $\Delta \sigma$ & $5.3 \%$ & $1.7 \%$ & $-7.0 \%$ \\
\hline \hline Ideologia & $\Delta \sigma$ & & $-1.4 \%$ & $1.2 \%$ \\
\hline \hline \% dotada & $\Delta \sigma$ & $-6.4 \%$ & & \\
\hline \hline Log f cadeiras distritais & $\Delta \sigma$ & & $-1.7 \%$ & $1.9 \%$ \\
\hline \hline Voto em 1994 & $\Delta \sigma$ & $-8.9 \%$ & & \\
\hline \hline membro da coalizão & $0 \rightarrow 1$ & & $4.0 \%$ & $-9.1 \%$ \\
\hline Comissão especial & $0 \rightarrow 1$ & & $13.6 \%$ & $-3.5 \%$ \\
\hline \hline PT & $0 \rightarrow 1$ & & & $-17.4 \%$ \\
\hline
\end{tabular}

Discutimos agora o apoio empírico a nossas hipóteses relacionadas com cada escolha de carreira, a começar pela aposentadoria. Nossa principal hipótese concernente a essa escolha sustenta-se muito bem. Um aumento de desvio padrão em idade oferece um aumento estimado de 5.3 pontos percentuais em aposentadoria. Isso significa que os mais velhos se aposentam, até mesmo os políticos brasileiros que costumam ser acusados de ter pensões de empregos anteriores, além de seus vencimentos como deputados!

Outro resultado interessante relaciona-se com as dotações orçamentárias. Um aumento de desvio padrão nessa variável leva a uma diminuição de 6 pontos percentuais na aposentadoria. O voto em 1994 teve um impacto semelhante, diminuindo em quase 9 pontos percentuais a probabilidade de aposentadoria. A conclusão que tiramos é que os deputados que são eleitoralmente vulneráveis e não 
têm tanto sucesso em seu atendimento clientelista - e portanto têm chances menores de se eleger - se aposentam com mais freqüência.

Nenhuma outra variável foi significativa nesse estágio. A saber, a aposentadoria não parece estar relacionada com antigüidade, liderança de comissão, posição ideológica ou filiação partidária. Isso oferece mais provas em apoio ao argumento de Pereira e Rennó (2001) de que a amostra de deputados que escolhem concorrer a um cargo não é extremamente distinta do resto da população. Por favor, observe-se que não incluímos posições de poder na instituição entre as variáveis independentes que explicam a aposentadoria. Dos 21 deputados que detêm tais posições, nenhum se aposentou e somente um decidiu concorrer a um cargo mais alto! Isso é uma prova de que o fato de deter posições de poder na Câmara está claramente relacionado com ambição intra-Câmara, pois é um incentivo a permanecer na casa, indicando ainda que os legisladores competentes preferem permanecer na câmara baixa ${ }^{12}$.

Em relação à escolha de concorrer a um cargo mais alto ou ficar na Câmara, além do fato de que todos os que detêm posições de poder na Câmara, uma das variáveis - comissão - mostrou resultados significativos. Os líderes das comissões especiais concorrem mais a postos mais altos. Com efeito, a liderança nessas comissões traz um aumento de cerca de 3 pontos percentuais na probabilidade de concorrer a cargo mais alto. A variável Comissão permanente, embora com o sinal correto, foi significante somente no nível de 112. Porém, nosso argumento principal se sustenta: esses dois tipos de comissões têm efeitos opostos sobre a escolha de carreira. Pertencer a uma comissão especial aumenta a visibilidade do deputado e, conseqüentemente, a probabilidade de buscar um cargo mais alto, enquanto que ser o presidente de uma comissão permanente é uma indicação de poder intraCâmara e leva o deputado a buscar a manutenção desse poder mediante a reeleição.

A variável posição ideológica teve um impacto positivo na probabilidade de concorrer à reeleição. Isso significa que os legisladores mais à direita tendem mais a concorrer à reeleição, em vez de tentar um cargo mais alto. Porém, ser membro da coalizão do governo, bem como membro do partido mais à esquerda (PT) aumenta a probabilidade de concorrer a um posto mais alto.

Como dar sentido a esses resultados? A Tabela 4 mostra que os efeitos das variáveis de partido (coalizão e PT) parecem ser muito maiores do que as do escore ideológico. Porém, o ponto da análise é que, para uma dada coalizão ou filiação ao Partido dos Trabalhadores, os membros mais à direita concorrem à reeleição ${ }^{13}$.

\footnotetext{
${ }^{12}$ Essa distribuição enviesada é provavelmente uma das razões para não encontrar efeito significante dessa variável no nível seguinte de decisão em nosso modelo, a saber, aquele que compreende concorrer à reeleição e concorrer a cargo mais alto.

${ }^{13}$ Isso é válido mesmo se trocarmos a variável ideologia por variáveis separadas que medem ideologia para membros e nãomembros da coalizão.
} 
Não há contradição, portanto, entre esses dois conjuntos de resultados.

Testamos o efeito quadrático da idade sobre a escolha entre reeleição e cargo mais alto. Os resultados oferecem algum suporte a nossas hipóteses. O termo quadrático foi positivo e significativo no nível de $5 \%$, mas o efeito linear não foi significante mesmo no nível generoso de $10 \%$. Membros relativamente jovens e relativamente velhos, em oposição aos resultados obtidos por Brace (1984) na Câmara de Deputados norte-americana, concorrem mais a cargos mais altos no Brasil.

Passando agora à discussão das variáveis mais pertinentes à nossa hipótese normativa, nossas estimativas indicam também um efeito significante do log do número de cadeiras distritais sobre a probabilidade de concorrer a um cargo mais alto. Um aumento do desvio padrão nessa variável diminui em $1.7 \%$ a disputa desses cargos. Portanto, os legisladores de estados menores concorrem mais a cargos mais altos, uma vez que é mais fácil para eles serem bem conhecidos em todo o distrito e, assim, menos arriscado concorrer a um cargo majoritário.

Por fim, as variáveis que medem o sucesso eleitoral, a concentração eleitoral e a dotação orçamentária não foram significativas para a diferenciação desses dois grupos: concorrer à reeleição ou a um cargo mais alto. Todas essas variáveis estão relacionadas com a probabilidade de ser reeleito e também não mostram resultados significativos quando incluídas separadamente. ${ }^{14}$ Além disso, a antigüidade também não teve um impacto significante sobre a escolha de carreira. Os membros mais antigos não tentam concorrer a cargos superiores mais do que outros membros. Esses resultados, junto com as conclusões sobre a posição de poder na Câmara e ser membro de comissão permanente, levantam sérias dúvidas sobre a adequação do argumento de Samuels de que os membros mais vulneráveis e menos competentes concorrem à reeleição. Nossos resultados mostram, ao contrário, um quadro diferente das decisões de carreira no Brasil.

\section{Conclusões}

As escolhas de carreira política no Brasil são fortemente orientadas pelos custos eleitorais de encarar eleições mais difíceis de vencer, tal como nos Estados Unidos, de acordo com a descrição de Rohde. Os deputados tentam concorrer a cargos mais altos somente quando sentem que possuem força eleitoral suficiente acumulada durante seus mandatos para encarar o risco de participar de uma

\footnotetext{
${ }^{14}$ No entanto, é importante reconhecer que, em modelos anteriores e menos parcimoniosos, encontramos diferenças interessantes entre aqueles dois grupos de legisladores. Por exemplo, os deputados que concorrem a cargos mais altos exibem uma estratégia dispersa em relação ao clientelismo. Em outras palavras, eles tentam não concentrar suas emendas em sua principal base eleitoral, tal como o fazem os que concorrem à reeleição. Esse resultado sugere que os deputados que tentam concorrer a posições reguladas por regras de pluralidade (governador e senador) estarão em situação melhor se dispersarem sua energia e suas políticas em todo o distrito eleitoral (estado).
} 
disputa em que o número de votos necessários para vencer é muito maior do que o suficiente para se reeleger. O fato de que o tamanho do distrito, que é um proxy do nível de competição nesse distrito, diminui a probabilidade de concorrer a um cargo mais alto indica que os deputados baseiam suas decisões relativas à carreira em avaliações do ambiente eleitoral, e isso é válido até mesmo para os mais competentes.

Os constrangimentos impostos pelo contexto eleitoral e pela avaliação dos deputados de seu desempenho são motivos fortes para que eles permaneçam na Câmara. Isso é claramente indicado pela falta de impacto estatístico de certas variáveis na diferenciação entre os que concorrem a cargos mais altos e aqueles que preferem concorrer à reeleição à Câmara. Os que preferem permanecer na Câmara são igualmente bem sucedidos na implementação de emendas orçamentárias, na presidência de comissões permanentes (mas não de comissões especiais) e não são candidatos mais vulneráveis do que aqueles que concorrem a cargos mais altos. Ademais, a maioria absoluta dos políticos que detêm uma posição poderosa na Câmara prefere permanecer nessa casa.

Estudos futuros deverão calibrar como a decisão de concorrer a prefeito em eleições de meio de mandato - e ser vitorioso nessa disputa - afeta a qualidade dos deputados federais que ficam na Câmara e suas escolhas de carreira. Samuels (a sair) mostrou que concorrer a prefeito é uma escolha muito freqüente feita pelos legisladores brasileiros e que essa escolha molda o comportamento deles dentro da Câmara durante os anos anteriores à eleição de meio de mandato. Uma tarefa que permanece por ser feita é contrastar como os deputados federais que concorrem a prefeito são diferentes dos que permanecem na Câmara. Além disso, é também importante verificar como aqueles que concorrem a prefeito, mas perdem e retornam à Câmara, se comparam com os outros deputados. Por fim, estudos futuros deveriam procurar explicar quais são os fatores relacionados com a eleição para cargo mais alto. Muito já foi dito sobre os determinantes da reeleição, mas nada se sabe sobre o que aumenta as chances de alcançar um posto mais alto.

Mas essas são metas para estudos futuros. Nosso objetivo aqui foi verificar quais são os fatores que influenciam a escolha do cargo ao qual concorrer. As implicações de nossos resultados com respeito à escolha entre se aposentar, permanecer na Câmara ou tentar um cargo mais alto para avaliações do funcionamento do poder legislativo no Brasil são bastante importantes nelas mesmas e diferentes de estudos anteriores (Samuels, 2000). O que descobrimos é que não são apenas os vulneráveis e incompetentes que concorrem à reeleição. Os que concorrem a cargos mais altos não são tão diferentes dos que permanecem na Câmara, indicando que as carreiras dentro da Câmara são muito atraentes. Se essa tendência se mantiver em eleições futuras, a influência da Câmara de Deputados e a qualidade de sua inserção nas tomadas de decisões no nível federal aumentarão 
ainda mais. Não resta dúvida de que um poder legislativo forte e eficiente é um dos alicerces da estabilidade democrática e nossos resultados indicam que a Câmara de Deputados brasileira, quando se trata das características dos deputados que decidem concorrer à reeleição, está avançando nessa direção. 


\section{BIBLIOGRAFIA}

AMES, Barry. 1995. "Electoral Strategy under Open-List Proportional Representation". American Journal of Political Science 39(2): 406-433.

BRACE, Paul. 1984. "Progressive Ambition in the House: A Probabilistic Approach". Journal of Politics 46(2): 556-571.

HALL, Richard 1996. Participation in Congress. New Haven: Yale University Press.

HALL, Richard L. e van Houweling, Robert P. 1995. "Avarice and Ambition in Congress:Representatives' Decisions to Run or Retire from the U.S. House". American Political Science Review, 89(1): 121-136.

HAUSMAN, Jerry e MACFADDEN, Daniel. 1984. "Specification Tests for the Multinomial Logit Model". Econometrica 52(5):1219-1240.

KIEWIET, Roderick e ZENG, Langche. 1993. "An Analysis of Congressional Career Decisions, 19471986”. American Political Science Review 87(4): 928-941.

LEONI, Eduardo. 2000. "Ideologia, Democracia e Comportamento Parlamentar: A Câmara dos Deputados no Brasil Pós-Constituinte". Tese de mestrado apresentada na Universidade de Brasília, Brasil.

. 2001. "Ideology and Roll Call voting in Brazil: Câmara dos Deputados 1991-1998". Trabalho apresentado na reunião da Midwest Political Science Association: Chicago, IL.

LONG, J. Scott. 1997. Regression Models for Categorical and Limited Dependent Variables. Thousand Oaks: Sage Publications.

MORGENSTERN, Scott. (a sair). "Conclusion: Explaining Legislative Politics in Latin America", in Legislatures and Democracy in Latin America. Scott Morgenstern e Benito Nacif (eds.) Nova York: Cambridge University Press.

MUELLER, Bernardo e PEREIRA, Carlos. 2001. "Executive's Strategic Choices on Coalition-Based Presidential System: The Case of Brazilian Decision-Making Process on the Annual Budget". Trabalho apresentado na conferência Brazilian Political Institutions in Comparative Perspective: The Role of Congress in Presidential Systems, Centre for Brazilian Studies, University of Oxford, 28-29 de maio.

NICOLAU, Jairo. 1999. Sistemas Eleitorais. Rio de Janeiro: Fundação Getúlio Vargas.

PEREIRA, Carlos e RENNÓ, Lúcio. 2001. "O Que é que o Reeleito Tem? Dinâmicas PolíticoInstitucionais Locais e Nacionais nas Eleições de 1998 para a Câmara dos Deputados". Dados 44(2): 323-362.

PEREIRA, Carlos. 2000. "What are the Conditions for the Presidential Success in the Legislative Arena? The Brazilian Electoral Connection". Dissertação de doutorado apresentada na The New School University, Nova York. 
Estratégias para sobreviver politicamente - Escolha de carreiras na Câmara de Deputados do Brasil

PEREIRA, Carlos e MUELLER, Bernardo. 2000. "Uma Teoria da Preponderância do Executivo: o Sistema de Comissões do Legislativo Brasileiro". Revista Brasileira de Ciências Sociais 15(43): 4567.

POOLE, Keith e ROSENTHAL, Howard. 1997. Congress: A Political-Economic History of Roll Call Voting. Nova York: Oxford University Press.

POLSBY, Nelson W. 1968. "The Institutionalization of the U.S. House of Representatives". American Political Science Review 62(1):144-168.

ROHDE, David. 1979. "Risk-Bearing and Progressive Ambition: The Case of Members of the United States House of Representatives”. American Journal of Political Science 23(1): 1-26.

SAMUELS, David. (a sair). "Progressive Ambition, Federalism, and Pork-Barreling in Brazil", in Legislatures and Democracy in Latin America. Scott Morgenstern e Benito Nacif (eds.) Nova York: Cambridge University Press.

SAMUELS, David. 2000. "Ambition and Competition: Explaining Legislative Turnover in Brazil". Legislative Studies Quarterly XXV: 481-498.

SANTOS, Fabiano. 1999. "Recruitment and Retention of Legislators in Brazil”. Legislative Studies Quarterly XXIV: 209-237.

. 2001. "Legislative Careers and "Congress-Dominated" Democracy: A comparison between Two Democratic Experiences in Brazil". Trabalho apresentado no XXIII Congresso Internacional da Latin American Studies Association, Washington, DC. 6-8 de setembro.

SCHLESINGER, Joseph. 1966. Ambition and Politics: Political Careers in the United States. Chicago: Rand McNally.

SHUGART, Matthew e CAREY, John. 1995. "Incentives to Cultivate a Personal Vote: A Rank Ordering of Electoral Formulas". Electoral Studies 14(4): 417-439.

ZHANG, Junsen e HOFFMAN Saul D. 1993. "Discrete Choice Logit Models: Testing the IIA Property". Sociological Methods \& Research 22(2):193-213.

Publicação autorizada pelos autores. Tradução de Pedro Maia Soares. 